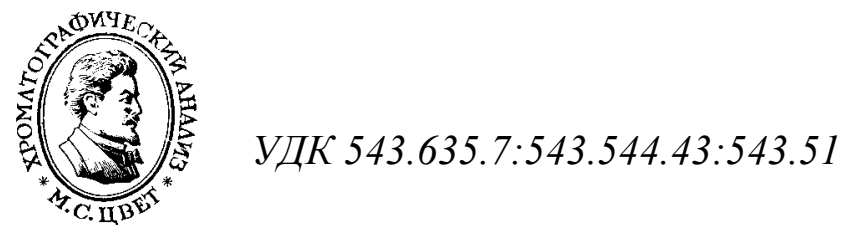

\title{
Методические аспекты \\ хромато-масс-спектрометрического анализа эфирного масла пихты сибирской
}

\author{
Сотникова Л.В. ${ }^{1}$, Созинов С.А. ${ }^{1,2}$, Горюнова П.В. ${ }^{1}$, \\ Ходыкина В.В. ${ }^{3}$, Иванова Н.В. ${ }^{2}$ \\ ${ }^{1}$ Научно-аналитический центр исследования химического состава и структуры углеродистых ве- \\ ществ (КемЦКП ФИЦ УУХ СО РАН), Кемерово \\ ${ }^{2}$ ФББОУ ВО Кемеровский государственный университет, Кемерово \\ ${ }^{3}$ ООО НПО «Алексеевское», Алексеевка
}

Поступила в редакцию 24.10.2017 г.

В работе на примере эфирного масла пихты сибирской обсуждаются особенности идентификации и определения количественного содержания соединений в сложной смеси органических веществ природного происхождения методом газожидкостной хроматографии и масс-спектрометрии (ГЖХ-МСД). Определены условия получения хроматографического профиля репрезентативных и характерных компонентов эфирного масла по ГОСТ ISO 10869-2015 с использованием капиллярной колонки HР-5ms. Показано влияние начальной температуры хроматографического анализа на степень перекрывания хроматографических пиков лимонена и $\beta$-фелландрена при совместном присутствии в эфирном масле пихты.

Ключевые слова: хроматография, масс-спектрометрия, терпены, лимонен, $\beta$-фелландрен, эфирное масло пихты сибирской.

\section{Methodological aspects: Gas Chromatographic-Mass Spectrometric Analysis of Essential Oil of Siberian fir}

\author{
Sotnikova L.V. ${ }^{1}$, Sozinov S.A. ${ }^{1,2}$, Goryunova P.V. ${ }^{1}$, \\ Khodykina V.V. ${ }^{3}$, Ivanova N.V. ${ }^{2}$ \\ ${ }^{I}$ Scientific analytical center for the study of the chemical composition and structure of carbonaceous sub- \\ stances (AC FRC CCC SB RAS), Kemerovo \\ ${ }^{2}$ Kemerovo State University, Kemerovo \\ ${ }^{3}$ LLC Scientific and Production Institution «Alekseevskoe», Alekseevka
}

The article is devoted to the compounds identification problem for complex mixtures of organic substances of natural origin by the example of Siberian fir essential oil. Natural essential oil components by using the gas-liquid chromatography on a non-polar phase capillary column HP-5ms was experimentally separated within the various temperature-programming modes. Chromatograms reported by the total ion current were used for identification of component peaks by mass spectrometry in the ChemStation program with the NIST11 mass spectrometer library. The result of the work are the conditions for the chromatographic separation of components of Siberian fir essential oil, which allow to detect all representative and characteristic components of a mixture of terpene compounds specified in GOST ISO 10869-2015. Examples of mass spectra of limonene and $\beta$-fellandrene show the possibilities and features of chromatography-mass spectrometry as an identification method for compounds of similar structure in the case of overlapping chromatographic peaks. Here is described an example of a mass spectrum of a high-similarity library sylvestrean mass spectrum, which is, however, the result of the addition of mass-spectrum lines of a pair of components (limo- 
nene, $\beta$-fellandrene). The effect of the initial chromatographic temperature (temperature range from $50{ }^{\circ} \mathrm{C}$ to $120^{\circ} \mathrm{C}$ ) on the degree of separation of the investigated components pair was researched. It is shown that under experimental conditions, with an increase in the initial temperature up to $85^{\circ} \mathrm{C}$, the sufficient separation of components is achieved in order to correctly identify the corresponding peaks in the automatic integration mode of the chromatogram with a quantitative evaluation of their content in the sample. An increase in the initial temperature above $90^{\circ} \mathrm{C}$ leads to a deterioration in the quality of the chromatogram. By the the result of the current paperwork, the conditions of carrying out of chromatography-mass-spectrometric analysis were selected, which allowed to reliably identify 13 characteristic components of a mixture of Terpenes of Siberian fir essential oil.

Keywords: chromatography, mass-spectrometry, terpenes, limonene, $\beta$-phellandrene, Siberian fir essential oil.

\section{Введение}

Хромато-масс-спектрометрия является методом выбора в анализе качественного и количественного состава сложных смесей природных органических соединений [1]. В последнее время к приоритетным задачам хромато-масс-спектрометрии относится аналитический контроль качества продуктов питания, биологически активных средств и объектов окружающей среды [2]. Отсутствие стандартных образцов для большинства компонентов сложных смесей природного происхождения, например, эфирных масел деревьев хвойных пород, приводит к необходимости разработки новых методик хромато-масс-спектрометрического определения [3]. Анализ работ, посвященных исследованию состава эфирных масел растений [3-7] показал, что существует ряд проблем в идентификации отдельных компонентов, относящихся к классу терпенов. Так в работах [3,5] в составе масел сосны и пихты не идентифицирован лимонен, тогда как в источниках $[4,6]$ содержится информация о наличии этого соединения в аналогичных маслах. В работе [4] в составе масла сосны не идентифицирован $\beta$-фелландрен. В [7] пара лимонен - $\beta$-фелландрен представлена, как пример двух компонентов, которые имеют мало различающиеся индексы удерживания и которые повсеместно сопутствуют один другому в смесях терпеноидов. При этом на хроматограммах, полученных с использованием фаз типа НP-5 пики данных соединений перекрываются, давая единственный пик неискаженной формы [7]. В связи с этим была поставлена задача разработать методические подходы для надежной идентификации компонентов эфирного масла пихты сибирской согласно нормативной документации [6].

Настоящая работа посвящена особенностям идентификации и количественного определения терпеновых соединений природного эфирного масла пихты сибирской с использованием метода хромато-масс-спектрометрии.

\section{Эксперимент}

Анализу методом хромато-масс-спектрометрии подвергали образцы, содержащие терпеновые соединения эфирного масла пихты сибирской. Для анализа 50 мкл эфирного масла смешивали с 1000 мкл этилового спирта, перемешивали в виале и помещали в автосамплер хроматографа Agilent $6890 \mathrm{~N}$, совмещенного с массселективным детектором (МСД) Agilent 5973 inert. Капиллярная колонка HP-5ms длинной 30 м с внутренним диаметром 0.25 мм, толщиной пленки неподвижной фазы 5\%-дифенил-95\%-диметилсилоксана 0.25 мкм. Условия проведения измерений: температура испарителя хроматографа - $250^{\circ} \mathrm{C}$; скорость газа-носителя гелия $1 \mathrm{~cm}^{3} /$ мин, режим ввода с делением потока, коэффициент деления потока - 100:1, объем аликвоты для анализа 0.2 мкл, программируемое повышение температуры колонки проводили в двух режимах. Режим 1: повышение температуры от $50^{\circ} \mathrm{C}$ с выдержкой 3 мин до $290^{\circ} \mathrm{C}$ со скоростью $5^{\circ} \mathrm{C} /$ мин. Режим 2: повышение температуры от 
$80^{\circ} \mathrm{C}$ с выдержкой 3 мин до $150^{\circ} \mathrm{C}$ со скоростью $7^{\circ} \mathrm{C} /$ мин, от $150^{\circ} \mathrm{C}$ до $260^{\circ} \mathrm{C}$ со скоростью $9^{\circ} \mathrm{C} /$ мин. Режим работы масс-спектрометра: ионизация электронным ударом при 70 эВ, температура источника ионов $230^{\circ} \mathrm{C}$, температура квадруполя $150^{\circ} \mathrm{C}$. Сигнал детектора записывали в режиме регистрации полного ионного тока. Идентификация компонентного состава пробы образца осуществлялась по масс-спектрам с использованием библиотеки спектров NIST11. Расчет относительного содержания компонентов проводили методом внутренней нормализации, с использованием программного обеспечения ChemStation.

\section{Обсуждение результатов}

Хроматографический профиль эфирного масла пихты сибирской, включающий репрезентативные и характерные компоненты, регламентирован ГОСТ [6]. Согласно этому межгосударственному стандарту, в пробе эфирного масла пихты сибирской следует определять содержание 13 основных компонентов, относящихся к классу терпеновых соединений. Поэтому, несмотря на то, что метод хромато-массспектрометрии позволяет определить большее количество компонентов эфирного масла [5], мы ограничили список исследуемых веществ компонентами, приведёнными в таблице 1.

Таблица 1. Хроматографический профиль репрезентативных и характерных компонентов эфирного масла пихты сибирской ГОСТ ISO 10869-2015.

\begin{tabular}{|c|c|c|c|}
\hline \multirow{2}{*}{ № } & \multirow{2}{*}{ Компонент } & \multicolumn{2}{|c|}{ Содержание } \\
\cline { 3 - 4 } & & $\min , \%$ & $\max , \%$ \\
\hline 1 & Сантен & 1.5 & 3.5 \\
\hline 2 & Трициклен & 1.5 & 3.5 \\
\hline 3 & $\alpha$-Пинен & 10.0 & 22.0 \\
\hline 4 & Камфен & 15.0 & 26.0 \\
\hline 5 & $\beta$-Пинен & 1.0 & 3.5 \\
\hline 6 & 3-Карен & 9.0 & 15.0 \\
\hline 7 & Лимонен & 4.0 & 10.0 \\
\hline 8 & $\beta$-Фелландрен & 1.5 & 3.0 \\
\hline 9 & Борнилацетат & 20.0 & 2.0 \\
\hline 10 & $\beta$-Кариофиллен & 0.5 & 0.1 \\
\hline 11 & Изоборнилацетат & - & 3.0 \\
\hline 12 & Борнеол & 1.0 & 0.9 \\
\hline 13 & $\alpha$-Гумулен & 0.3 & \\
\hline
\end{tabular}

Хроматограмма, полученная в условиях программируемого повышения температуры в режиме 1 и содержащая пики основных терпеновых соединений масла пихты сибирской представлена на рисунке 1. Результаты расчета относительного содержания компонентов и их идентификации в автоматическом режиме интегрирования с распознаванием по библиотеке масс-спектров представлены в таблице 2. Пик считался идентифицированным, если степень подобия масс-спектра компонента с библиотечным масс-спектром соединения выше 90\%.

Из рисунка 1 видно, что пики основных компонентов пробы на хроматограмме хорошо разрешены. Из сравнения данных таблиц 1 и 2, можно видеть, что пробы эфирного масла по составу основных компонентов отличаются от соединений, перечисленных в ГОСТ ISO 10869-2015 тем, что в их составе не идентифицируются лимонен и $\beta$-фелландрен. Однако в области характерных для этих соединений времен удерживания регистрируется интенсивный, симметричный пик $\left(\mathrm{t}_{\mathrm{R}}=10.99\right.$ мин $)$, соот- 
ветствующий ему масс-спектр имеет высокую степень подобия (91.4\%) библиотечному масс-спектру сильвестрена (рис. 3а).

Таблица 2. Наименование и относительное содержание компонентов эфирного масла пихты сибирской, анализ с использованием режима 1.

\begin{tabular}{|c|c|c|c|c|}
\hline № п/п & $\begin{array}{c}\text { Время } \\
\text { удерживания }\left(\mathrm{t}_{\mathrm{R}}\right), \\
\text { мин. }\end{array}$ & Наименование компонента & Формула & $\begin{array}{c}\text { Относительное } \\
\text { содержание, } \\
\%\end{array}$ \\
\hline 1 & 6.64 & Сантен & $\mathrm{C}_{9} \mathrm{H}_{14}$ & 2.8 \\
\hline 2 & 7.71 & Трициклен & $\mathrm{C}_{10} \mathrm{H}_{16}$ & 2.8 \\
\hline 3 & 8.06 & $\alpha$-Пинен & $\mathrm{C}_{10} \mathrm{H}_{16}$ & 14.6 \\
\hline 4 & 8.51 & Камфен & $\mathrm{C}_{10} \mathrm{H}_{16}$ & 21.8 \\
\hline 5 & 9.38 & $\beta$-Пинен & $\mathrm{C}_{10} \mathrm{H}_{16}$ & 2.1 \\
\hline 6 & 9.84 & $\beta$-Мурсен & $\mathrm{C}_{10} \mathrm{H}_{16}$ & 0.5 \\
\hline 7 & 10.42 & 3-Карен & $\mathrm{C}_{10} \mathrm{H}_{16}$ & 15.4 \\
\hline 8 & 10.99 & Сильвестен & $\mathrm{C}_{10} \mathrm{H}_{16}$ & 8.1 \\
\hline 9 & 12.86 & Терпинолен & $\mathrm{C}_{10} \mathrm{H}_{16}$ & 1.6 \\
\hline 10 & 15.22 & Борнеол & $\mathrm{C}_{10} \mathrm{H}_{18} \mathrm{O}$ & 1.1 \\
\hline 11 & 18.66 & Борнилацетат & $\mathrm{C}_{12} \mathrm{H}_{20} \mathrm{O}_{2}$ & 28.1 \\
\hline 12 & 22.25 & $\beta$-Кариофиллен & $\mathrm{C}_{15} \mathrm{H}_{24}$ & 0.8 \\
\hline 13 & 23.11 & $\alpha$-Гумулен & $\mathrm{C}_{15} \mathrm{H}_{24}$ & 0.4 \\
\hline
\end{tabular}

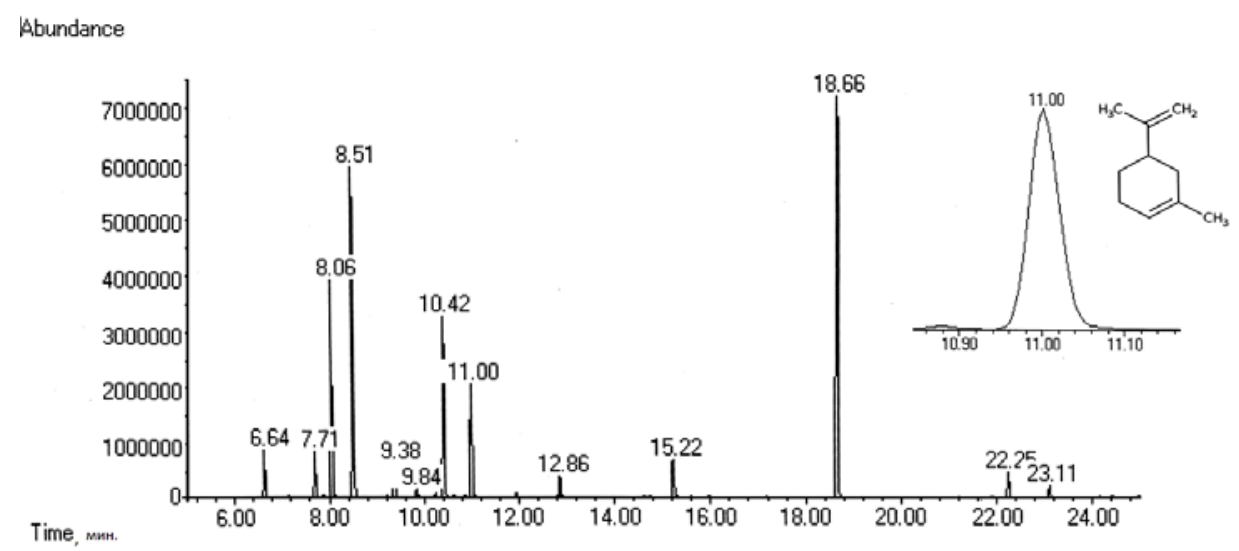

Рис. 1. Хроматограмма эфирного масла пихты сибирской, включающая 13 основных пиков терпеновых соединений. Колонка - HP-5ms (30 м, 0.25 мм, 0.25 мкм); детектор МСД, режим 1. Участок хроматограммы с интенсивным пиком симметричной формы, идентифицированным как сильвестрен.

Сильвестрен - синтетическое соединение, но иногда идентифицируется как компонент эфирных масел растений [8]. Для выяснения природы пика с временем удерживания 10.99 мин изменили режим программируемого повышения температуры в ходе хроматографического анализа. На рисунке 2 представлена хроматограмма пробы эфирного масла пихты, полученная с использованием режима 2. Результаты идентификации компонентов по библиотеке масс-спектров и расчета их относительного содержания представлены в таблице 3.

Видно, что использование режима 2 (рис. 2.) позволяет добиться лучшего разделения компонентов. Частично перекрывающиеся пики (в области 6.53 мин) идентифицируются в ручном режиме по библиотеке масс-спектров NIST 11, как лимонен (рис. 3б) и $\beta$-фелландрен (рис. 3в), однако с помощью программного обеспечения пики пары компонентов - лимонена и $\beta$-фелландрена интегрируются, как один пик. 


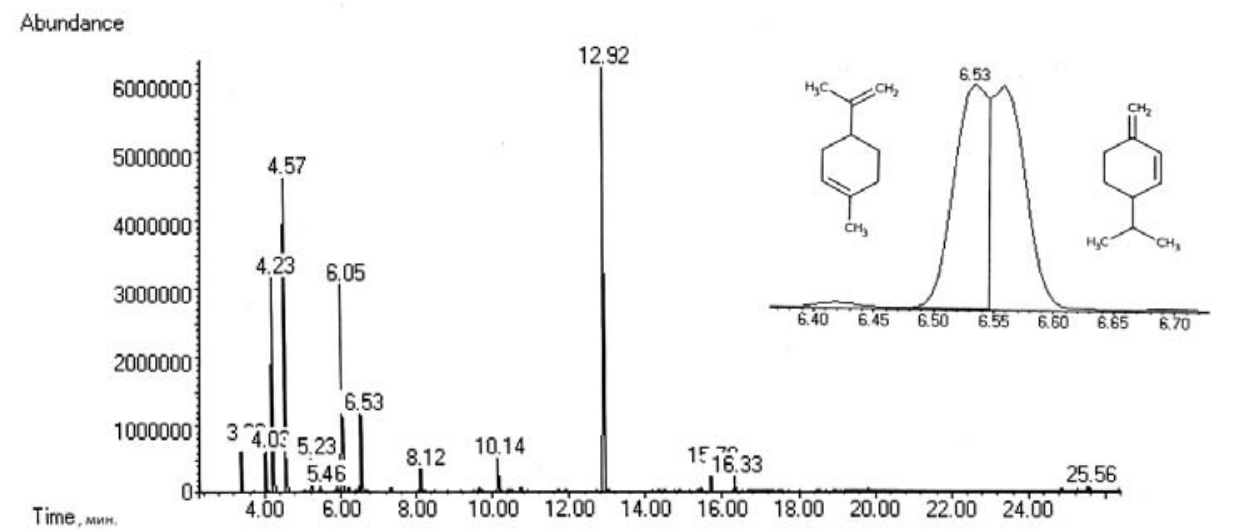

Рис. 2. Хроматограмма эфирного масла пихты сибирской. Колонка - HP-5ms (30 м, 0.25 мм, 0.25 мкм); детектор МСД, режим 2. И участок хроматограммы с частично перекрывающимися пиками лимонена и $\beta$-фелландрена.

Таблица 3. Наименование и относительное содержание компонентов эфирного масла пихты сибирской, анализ с использованием режима 2.

\begin{tabular}{|c|c|c|c|c|}
\hline № п/п & $\begin{array}{c}\text { Время } \\
\text { удерживания }\left(\mathrm{t}_{\mathrm{R}}\right), \\
\text { мин. }\end{array}$ & $\begin{array}{c}\text { Наименование } \\
\text { компонента }\end{array}$ & $\begin{array}{c}\text { Форму- } \\
\text { ла }\end{array}$ & $\begin{array}{c}\text { Относительное } \\
\text { содержание, } \\
\%\end{array}$ \\
\hline 1 & 3.39 & Сантен & $\mathrm{C}_{9} \mathrm{H}_{14}$ & 2.6 \\
\hline 2 & 4.03 & Трициклен & $\mathrm{C}_{10} \mathrm{H}_{16}$ & 2.7 \\
\hline 3 & 4.23 & $\alpha$-Пинен & $\mathrm{C}_{10} \mathrm{H}_{16}$ & 13.5 \\
\hline 4 & 4.57 & Камфен & $\mathrm{C}_{10} \mathrm{H}_{16}$ & 23.3 \\
\hline 5 & 5.23 & $\beta$-Пинен & $\mathrm{C}_{10} \mathrm{H}_{16}$ & 2.0 \\
\hline 6 & 5.46 & $\beta$-Мурсен & $\mathrm{C}_{10} \mathrm{H}_{16}$ & 0.4 \\
\hline 7 & 6.05 & $3-$-Карен & $\mathrm{C}_{10} \mathrm{H}_{16}$ & 12.9 \\
\hline 8,9 & 6.53 & Лимонен + $\beta$-Фелландрен & $\mathrm{C}_{10} \mathrm{H}_{16}$ & 8.1 \\
\hline 10 & 8.12 & Терпинолен & $\mathrm{C}_{10} \mathrm{H}_{16}$ & 1.3 \\
\hline 11 & 10.14 & Борнеол & $\mathrm{C}_{10} \mathrm{H}_{18} \mathrm{O}$ & 1.9 \\
\hline 12 & 12.92 & Борнилацетат & $\mathrm{C}_{12} \mathrm{H}_{20} \mathrm{O}_{2}$ & 29.7 \\
\hline 13 & 15.70 & $\beta$-Кариофиллен & $\mathrm{C}_{15} \mathrm{H}_{24}$ & 1.1 \\
\hline 14 & 16.33 & $\alpha$-Гумулен & $\mathrm{C}_{15} \mathrm{H}_{24}$ & 0.6 \\
\hline
\end{tabular}

Масс-спектры трех терпеновых соединений: сильвестрена, лимонена и $\beta$ фелландрена подобны по набору пиков фрагментных ионов в спектрах (рис. 3а, 3б, 3в), что является обычным для соединений близкой структуры. В таких случаях для идентификации соединения одним из критериев является соответствие соотношений интенсивностей пиков основных фрагментных ионов. Поэтому для достоверной идентификации терпеновых соединений требуется высокая (более 90\%) степень подобия масс-спектра анализируемого соединения библиотечному спектру [7]. В нашем случае обращает на себя внимание высокая степень подобия (91.4\%) компонента с временем удерживания 10.99 мин (режим 1), сильвестрену. Объяснение этому факту было найдено в ходе сравнения масс-спектров. Характерными пиками в массспектрах лимонена, $\beta$-фелландрена и сильвестрена являются пики, соответствующие фрагментным ионам с $m / z-68,93$ и молекулярному иону с $m / z 136$ (рис. 3.). Если сравнить относительные интенсивности характеристических ионов, то можно видеть (таблица 4), что суммарный масс-спектр лимонена и $\beta$-фелландрена, находящихся в соотношении компонентов 1:1, в большей степени подобен масс-спектру сильвестрена, чем лимонену или $\beta$-фелландрену по отдельности. Данная ситуация интересна 
и тем, что лимонен и $\beta$-фелландрен в эфирном масле пихты сибирской на практике часто находятся в соотношении близком к 1:1.
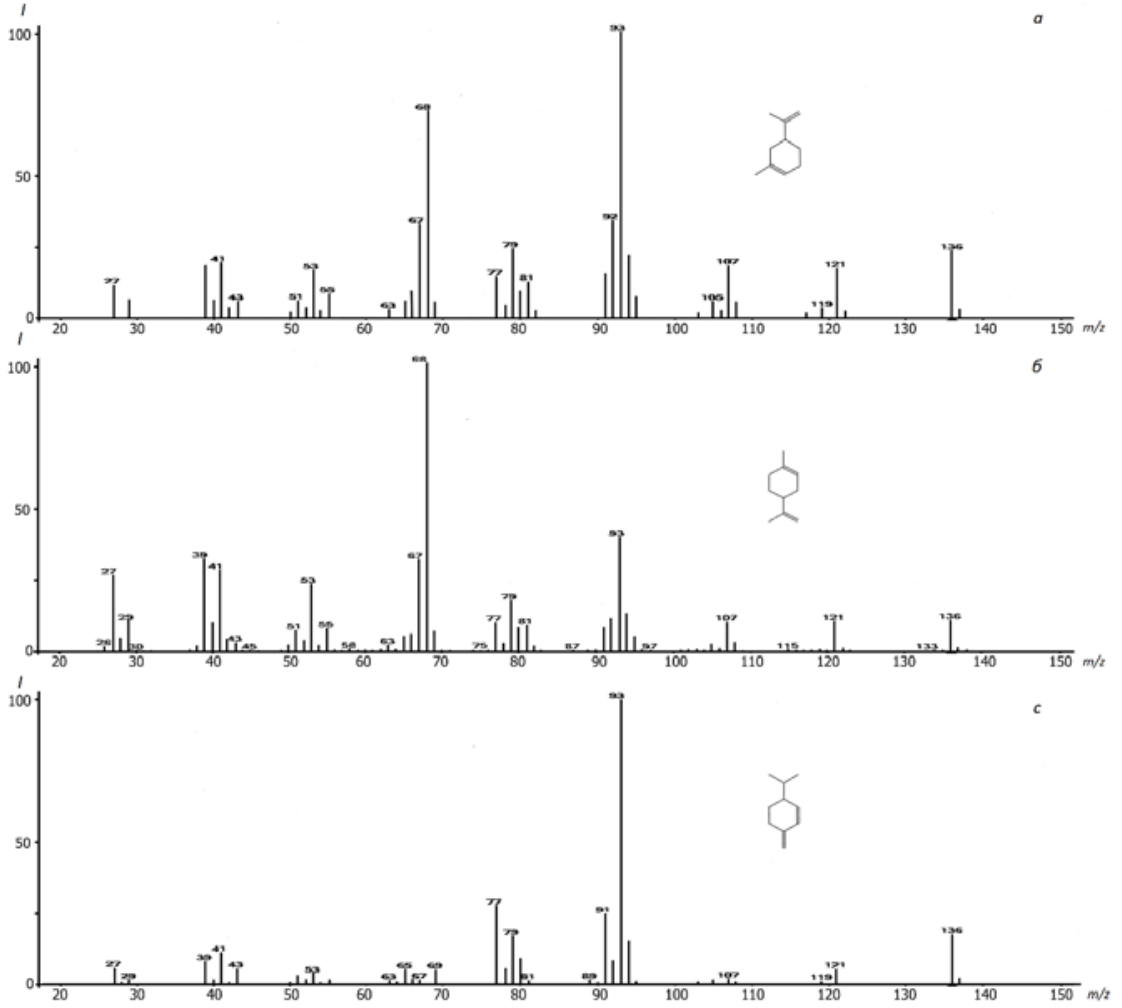

Рис. 3. Масс-спектры терпенов: сильвестрена (Sylvestrene) (a); лимонена (DLimonene) (б); $\beta$-фелландрена (Phellandrene) (c).

Таблица 4. Сопоставление относительной интенсивности характеристических фрагментных ионов в масс-спектрах D-лимонена, $\beta$-фелландрена и сильвестрена.

\begin{tabular}{|c|c|c|c|c|}
\hline \multirow{3}{*}{$\begin{array}{c}\text { Массовые чис- } \\
\text { ла фрагмент- } \\
\text { ных ионов } \\
(m / z)\end{array}$} & \multicolumn{4}{|c|}{ Интенсивность пиков ионов, \% } \\
\hline & \multicolumn{3}{|c|}{ Индивидуальные компоненты } & \multirow{2}{*}{$\begin{array}{c}\text { Смесь компонен- } \\
\text { тов в соотноше- } \\
\text { нии } 1: 1 \\
\text { D-Лимонен }+\beta- \\
\text { Фелландрен } \\
\end{array}$} \\
\hline & Сильвестрен & D-Лимонен & $\beta$-Фелландрен & \\
\hline 27 & 12.3 & 27.7 & 6.2 & 24.2 \\
\hline 41 & 20 & 27.7 & 10.8 & 27.5 \\
\hline 53 & 17 & 23 & 3 & 18.5 \\
\hline 68 & 74 & 100 & - & 71.4 \\
\hline 79 & 24.6 & 17 & 17 & 24.3 \\
\hline 93 & 100 & 40 & 100 & 100 \\
\hline 107 & 18.5 & 10.8 & 3 & 9.9 \\
\hline 121 & 17 & 10.8 & 7.7 & 13.2 \\
\hline 136 & 24.6 & 10.8 & 18.5 & 20.9 \\
\hline
\end{tabular}

По нашему мнению, причиной несогласованности результатов определения состава эфирных масел [3-5] является неверная идентификация пика, образованного перекрывающимися пиками лимонена и $\beta$-фелландрена. При этом заподозрить ошибку идентификации можно либо, анализируя пробу с применением стандартов двух этих компонентов, либо обладая информацией об их обязательном присутствии в пробе. 
Использовать режим 2 при проведении рутинного анализа состава эфирного масла неудобно т.к. сильное перекрывание пиков лимонена и $\beta$-фелландрена требует использовать интегрирование в ручном режиме. Поэтому для системы ГЖХ-МСД режим 2 был модифицирован. Варьирование величины начальной температуры хроматографического анализа в диапазоне от 50 до $120^{\circ} \mathrm{C}$ позволило наблюдать изменение степени разделения пиков исследуемой пары компонентов. На рисунке 4 представлены участки хроматограмм с пиками лимонена и $\beta$-фелландрена, полученные при различных значениях начальной температуры хроматографического анализа. Из данных рисунка 4 и таблицы 5 видно, что с повышением начальной температуры до $85^{\circ} \mathrm{C}$ достигается удовлетворительное разделение пиков указанных компонентов. Увеличение температуры свыше $90^{\circ} \mathrm{C}$ улучшает разделение, но отрицательно сказывается на качестве всей хроматограммы, поэтому оптимальную величину начальной температуры следует выбирать в диапазоне $85-90^{\circ} \mathrm{C}$.

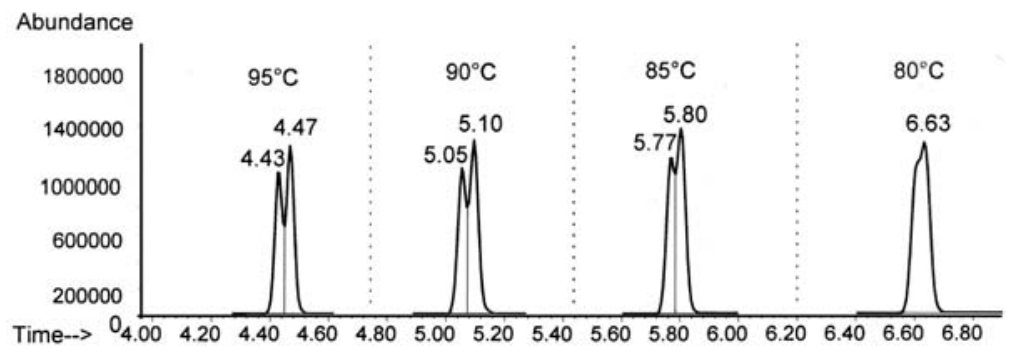

Рис. 4. Участки хроматограмм с пиками лимонена и $\beta$-фелландрена, цифрами указаны значения начальных температур хроматографического анализа и времена удерживания. Колонка - НР-5ms (30 м, 0.25 мм, 0.25 мкм); детектор МСД.

Таблица 5. Начальная температура хроматографического анализа и результат интегрирования ChemStation

\begin{tabular}{|c|c|c|c|c|}
\hline № ח/п & $\mathrm{T}_{\text {начальная, }}{ }^{\circ} \mathrm{C}$ & $\begin{array}{c}\text { Время удерживания } \\
\left(t_{R}\right), \text { мин. }\end{array}$ & $\begin{array}{l}\text { Относительное } \\
\text { содержание, \% }\end{array}$ & $\begin{array}{c}\text { Идентифицированный } \\
\text { компонент }\end{array}$ \\
\hline 1 & 50 & 10.99 & 8.3 & $\mathrm{C}$ \\
\hline 2 & 80 & 6.63 & 10.2 & 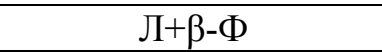 \\
\hline \multirow{2}{*}{3} & \multirow{2}{*}{85} & 5.77 & 4.6 & Л \\
\hline & & 5.80 & 5.1 & $\beta-\Phi$ \\
\hline \multirow{2}{*}{4} & \multirow{2}{*}{90} & 5.05 & 4.7 & $\pi$ \\
\hline & & 5.10 & 5.1 & $\beta-\Phi$ \\
\hline \multirow{2}{*}{5} & \multirow{2}{*}{95} & 4.43 & 4.8 & Л \\
\hline & & 4.47 & 5.7 & $\beta-\Phi$ \\
\hline \multirow{2}{*}{6} & \multirow{2}{*}{100} & 3.84 & 5.2 & $\pi$ \\
\hline & & 3.88 & 5.4 & $\beta-\Phi$ \\
\hline \multirow{2}{*}{7} & \multirow{2}{*}{120} & 2.70 & 4.9 & $\pi$ \\
\hline & & 2.73 & 5.7 & $\beta-\Phi$ \\
\hline
\end{tabular}

Другим методом повышения эффективности разделения исследуемых компонентов, стало изменение параметров колонки. Используя колонку CR-5 (аналог HP$5)$ той же длины, но с большим внутренним диаметром (0.32 мм) и толщиной пленки неподвижной фазы - 0.5 мкм были получены пики с удовлетворительным разрешением. Однако совмещение такой колонки с МСД не рекомендуется. Колонка CR-5 использована при детектировании сигнала пламенно-ионизационным детектором (ПИД) в режиме 2 с начальной температурой программирования $80^{\circ} \mathrm{C}$. На рисунке 5 приведена хроматограмма для пробы эфирного масла, полученная в указанных условиях. 


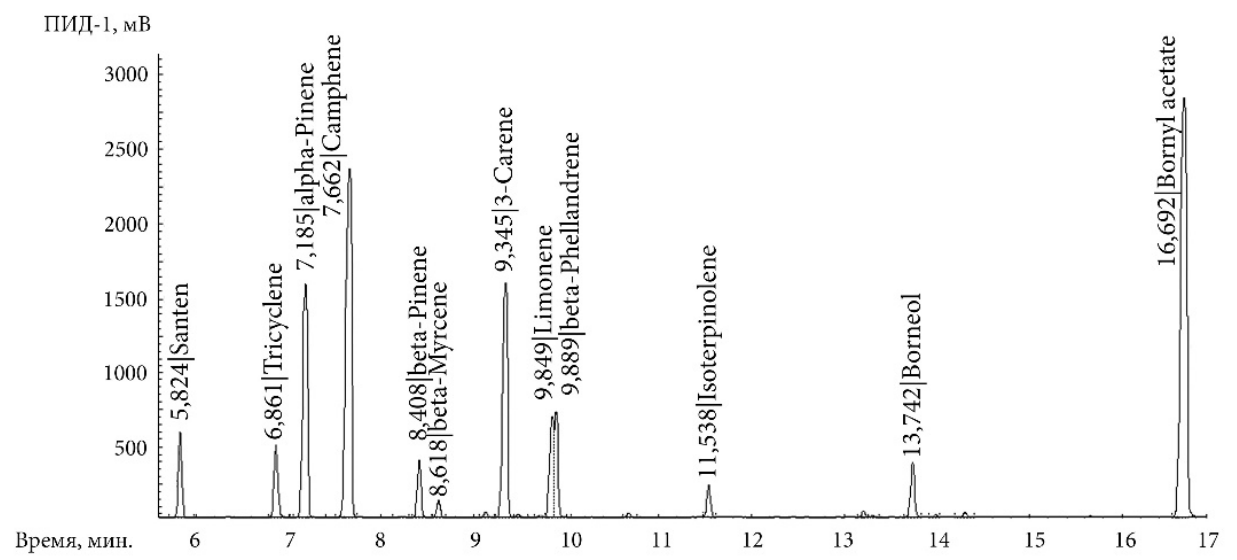

Рис. 5. Фрагмент хроматограммы эфирного масла пихты. Условия анализа: колонка - CR-5 (30 м, 0.32 мм, 0.5 мкм); детектор ПИД; режим 2.

\section{Заключение}

В работе определены условия проведения хромато-масс-спектрометрического анализа, позволяющие надежно идентифицировать и определить содержание 13 характерных компонентов эфирного масла пихты сибирской с использованием колонок с неподвижной фазой 5\%-дифенил-95\%-диметилсилоксан. Показано, что степень перекрывания пиков лимонена и $\beta$-фелландрена при использовании колонок типа НР-5 зависит от величины начальной температуры режима программирования хроматографического анализа. Проведён анализ проб эфирного масла пихты сибирской с масс-спектрометрическим и пламенно-ионизационным детектированием. Для разделения пиков характерных компонентов эфирного масла с детектированием МСД рекомендуется начальная температура от 85 до $90^{\circ} \mathrm{C}$.

\section{Работа выполнена на оборудовании Научно-аналитического иентра исследо- вания химического состава и структуры углеродистых веществ \\ (КемЦКП ФИЦ УУХ СО РАН).}

\section{Список литературы}

1. Лебедев А.Т. Масс-спектрометрия в органической химии. М. БИНОМ. Лаборатория знаний. 2003., 493 с.

2. Клюев Н.А., Бродский Е.С. // Рос. хим. ж. 2002. Т. 46. № 4. С. 57-63.

3. Нарчуганов А.Н., Ефремов А.А. // Химия растительного сырья. 2013. № 1. С. 125-128.

4. Чекушкина Н.В., Невзорова Т.В., Ефремов А.А. // Химия растительного сырья. 2008. № 2. C. 87-90.

\section{References}

1. Lebedev A.T., Mass-spektrometrija v organicheskoj himii, M., BINOM, Laboratorija znanij, 2003, 493 p.
5. Сидельников В.Н., Патрушев Ю.В., Сизова Н.В., Петренко Т.В. // Химия растительного сырья. 2003. № 1. С. 79-85.

6. ГОСТ ISO 10869-2015. Масло эфирное сибирской пихты (Abies sibirica Lebed) Texнические условия. С. 11.

7. Ткачёв А.В. Исследование летучих веществ растений. Новосибирск. «Офсет». $2008.969 \mathrm{c}$.

8. Zoghbi M., Pereira R., Lima G., Bastos M. // Quim. Nova. 2014. Vol. 37. No 7. pp. 11881192.

2. Kljuev N.A., Brodskij E.S., Russ. J. Gen. Chem., 2002, Vol. 46, No 4, pp. 57-63. 
3. Narchuganov A.N., Efremov A.A., Himija rastitel'nogo syr'ja, 2013, No 1, pp. 125-128.

4. Chekushkina N.V., Nevzorova T.V., Efremov A.A., Himija rastitel'nogo syr'ja, 2008, No 2, pp. 78-90.

5. Sidel'nikov V.N., Patrushev Ju.V., Sizova N.V., Petrenko T.V., Himija rastitel'nogo syr'ja, 2003, No 1, pp. 79-85.

6. GOST ISO 10869-2015. Essential oil of fir needle, Siberian (Abies sibirica Lebed). Specifi-

Сотникова Лариса Владимировна - н.с., к.х.н., доцент, КемЦКП, ФИЦ УУХ СО РАН, Кемерово

Созинов Сергей Анатольевич - с.н.с., к.ф.м.н., руководитель, КемЦКП ФИЦ УУХ СО РАН, Кемерово

Горюнова Полина Валентиновна - н.с., к.Х.н., КемЦКП ФИЦ УУХ СО РАН, Кемерово

Ходыкина Валентина Васильевна - химикоператор, ООО Научно-производственное учреждение «Алексеевское», Опытная станция, Алексеевка

Иванова Наталья Владимировна - доцент кафедры аналитической и неорганической химии ИФИ Кемеровского государственного университета, Кемерово cations. Moscow, Standartinform Publ., 2016, 11 p. (In Russian)

7. Tkachjov A.V., Issledovanie letuchih veshhestv rastenij. Novosibirsk, «Ofset», 2008, 969 p.

8. Zoghbi M., Pereira R., Lima G., Bastos M., Quim. Nova, 2014, Vol. 37, No 7, pp. 11881192.

Sotnikova Larisa V. - Research Associate, $\mathrm{Ph} . \mathrm{D}$. (chemistry), associate prof., AC FRC CCC SB RAS, Kemerovo, e-mail: lorikkemerovo@gmail.com

Sozinov Sergey A. - Senior Researcher, Ph.D. (physmathematical), Head, AC FRC CCC SB RAS, Kemerovo, e-mail: sozinov71@mail.ru

Goryunova Polina V. - Research assistant, Ph.D. (chemistry), AC FRC CCC SB RAS, Kemerovo, e-mail: lpv110185@rambler.ru

Khodykina Valentina V. - chemical operator, LLC Scientific and Production Institution "Alekseevskoe", Experimental station, Alekseevka, email: valentina.hodikina@mail.ru

Ivanova Natalia V. - Ph.D. (chemistry), Associate Prof., Department of Analytical and Inorganic Chemistry, IBR, Kemerovo State University, Kemerovo, e-mail: sayganta@mail.ru 